\title{
Impact study of single stage and multi stage abrasive machining on static strength of lap ad- hesive joints of mild steel
}

\author{
Anna Rudawska ${ }^{1}$, Izabela Miturska ${ }^{1, *}$ \\ ${ }^{1}$ Department of Production Engineering, Faculty of Mechanical Engineering, Lublin University of \\ Technology, address: ul. Nadbystrzycka 36, 20-618 Lublin
}

\begin{abstract}
The article presents the results of research on the influence of one of the technological factors, which is preparation of C45 steel surface before bonding. Seven methods of surface preparation performed by mechanical abrasive grinding tools of different gradations: P40, P120, P320 and P500 in various combinations one-stage or multi stage and degreasing were analysed. The obtained results were subjected to a statistical one-way analysis of variance, which proved that the strength of the adhesive joints depends on the appropriate choice of tools used for abrasive processing, while preparing the surface of the joints before bonding.
\end{abstract}

Keywords: abrasive machining, surface preparation, adhesive joints, static strength

\section{Introduction}

Cohering is one of the methods of bonding that often uses a different material than the one the bonded elements are made of. Adhesives have the capacity to produce the force of adhesion to the bonded elements. Adhesion process involves putting a thin layer of an adhesive between the surfaces that are bonded by adhesive and cohesive forces, i.e. the force of internal cohesion of materials. Moreover, adhesives can also protect from corrosion and serve as leak stoppers $[1,2]$.

The usage of adhesives on an industrial scale dates back to the 20th century, when modern types of glue, such as synthetic phenolic and epoxy adhesive were invented. It made it possible to use the adhesion process for bonding elements made of both wood and metal. The first sectors of industry where structural adhesives were used on an industrial scale were aviation, automotive and rail industries. A need for such type of bonding method stems from using new types of materials in different constructions, such as polymeric composites, for bonding of which adhesion in the most effective and optimal method [2]. However, adhesion cannot be used everywhere. There are lots of sectors where, due to technological and constructional reasons, this method of bonding cannot be used. It results from some limitations of adhesive bonds, as well as their disadvantageous features, such as fast ageing

\footnotetext{
* Corresponding author: i.miturska@pollub.pl

Reviewers: František Holešovský, Dana Stančeková
} 
or instability of various structural and mechanic properties in specific exploitation conditions [2].

The adhesion process involves numerous technological and constructional factors that impact the adhesive joints' strength. They are, among others: the method of the bonded materials' surface preparation, type of adhesive and method of its application on the bonded surfaces, conditions of the adhesive-bonded joint's hardening depending on, among others, adhesive type (temperature, time and pressure) and seasoning conditions. The most vital constructional factors are shape and dimensions of a joint (depending on, among others, geometric features of the bonded materials, as well as the type of an adhesive joint load.

Changes within aforementioned factors may have different impact on the specific joints' properties. Problems describing impact of these factors on the adhesive joints have been described in many works and articles $[3,4]$. However, due to specification of the joints that are the subject of the present article, it is necessary to carry out a study related with impact of these factors on particular cases and applications. A change within the aforementioned factors in case of a particular joint may impact its properties in a quite different way, e.g. another material, including its strength properties.

The present article is focused on the examination of impact of the C45 low alloy steel preparation to the process of bonding, which constitutes one of the technological factors. A method of the steel sheet surface preparation used in the study was one- and multi-stage mechanical working with use of coated abrasives with abrasive grits of different gradation. Also, measurements of the surface roughness after the considered types of the surface treatment were carried out. The analysis included seven methods of surface preparation by means of mechanical treatment with use of coated abrasives with abrasive grits of different gradation: P40, P120, P320 and P500 in various combinations, as well as degreasing.

\subsection{Factors impacting the adhesive joints' strength}

When making adhesive joints, it is necessary to get familiar with numerous problems related with adhesive technology, as well as to adhere to guidelines concerning a particular type of joint. One of the most vital matters is knowledge of time and properties of the bonded components as they directly influence the choice of a proper method of surface preparation and of type of adhesive that should be used. The adhesive joint construction's geometry and dimensions have direct influence on the adhesive application method, choice of technological instrumentation to be used, as well as on the value of pressure put during the curing process. The assumed exploitation conditions connected with a type of load on the adhesive joint and type of environment in which the joint will be exploited also influence the choice of a particular type of joint and type of adhesive.

\subsection{Preparation of surface for the adhesive process}

Surface preparation operations are one of the first technological stages of the bonding process. They are of great importance due to the necessity of establishing proper adhesive properties of the surfaces that have influence on their adhesive capacity, in turn, leads to creating a durable adhesive joint. Surface treatment before bonding may be divided into three groups: initial surface preparation, basic surface treatment and additional surface treatment. A division of methods in each of the groups is presented in Figure 1.

The choice of method of surface preparation for the bonding process depends on numerous factors. The most important one, though, is a type of the material. When it comes to the low alloy steel, there are some recommendations related with the surface preparation process [5-7]. Due to the $\mathrm{C} 45$ steel characteristics that make mechanical working easier, the 
recommended methods are: grinding, abrasive machining, vapour blasting, sandblasting, shot blasting, superfinishing, polishing. Abrasive machining with use of coated abrasives of different graininess, as well as degreasing were selected as the surface preparation methods for the study needs.

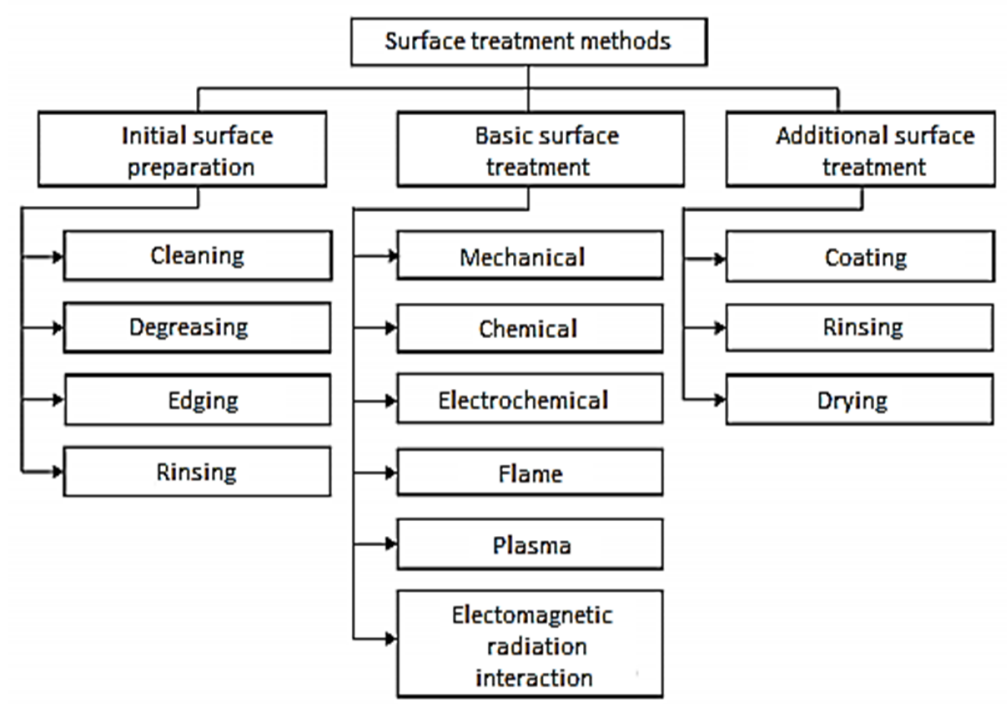

Fig. 1. Types of surface treatment used in the bonding technology [4]

Proper preparation of the material surface is a vital condition that has to be fulfilled in order to obtain adhesive joints with the assumed properties. After the surface is prepared properly, all joining mechanisms should start working - both physical, including the mechanical, as well as chemical ones. This very first stage of the bonding process should ensure obtaining as strong adhesive joints as possible. The aim of surface preparation is also to remove all kinds of impurities from the joined elements' surface, as they weaken adhesive joints. Another reason for this is to change the surface geometric structure (by increasing the surface roughness properly), thanks to which the real surface moistured by adhesive is increased and penetration of adhesive into the joined surfaces' structure is better (Fig. 2).

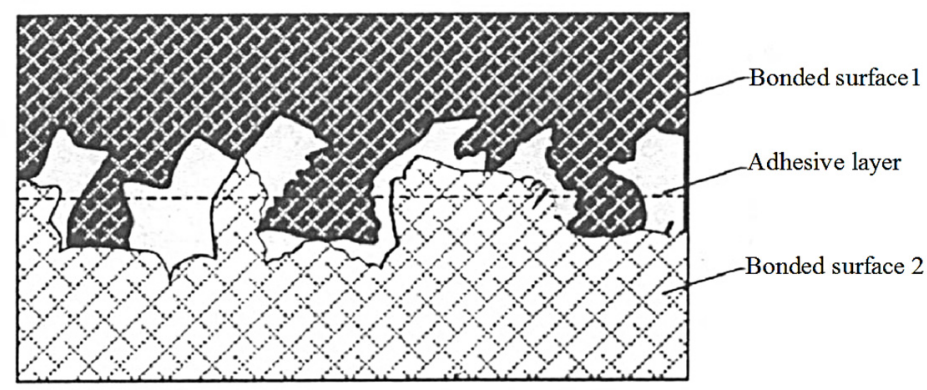

Fig. 2. Scheme of an adhesive joint of surface area of two solids joint with adhesive [4]

The increase in the given material's surface roughness results in a higher number of cavities with irregular shapes the adhesive may penetrate. Adhesive penetration depends on its adhesiveness, temperature, pressure, penetration time, and the aforementioned cavities' section and depth. 


\subsection{Degreasing and mechanical working}

Mechanical working is classified as one of the basic methods of surface treatment of numerous materials aimed at bonding [7]. Mechanical working makes it possible to increase the surface area, which results in possible increase in the surface energy and change in the range of the intermolecular forces saturation [8]. Surface geometry is an inseparable aspect of mechanical working. It is realised by the profile and roughness measuring. Problems related with surface roughness during creating adhesive joints and with the mechanical adhesion theory have been referred to in the references [9-11]. One of the most popular methods of mechanical working is usage of the coated abrasives, which are widely used in treatment of materials aimed at joining due to, among others, a possibility of application in various conditions. Another important factor is the ease of obtaining non-directional structure of treatment marks, which is beneficial and desired especially in structural joining.

Degreasing is often used as a method of surface preparation before the joining process, including bonding, as it removes all kinds of dust and adhesive impurities that are often residues from the previous working, including machining, or anti-corrosion protection and lubricants $[12,13]$. Degreasing may be conducted in different ways using specific degreasing agents. Producers of adhesive often offer ready-to-use products of certain characteristics and aimed at specific use.

\section{Experimental studies}

Experimental studies included creating adhesive joints of C45 steel sheets, whose surface was subjected to different methods of surface treatment. Surface structure was assessed by measuring the roughness parameters and making the surface analysers. The force breaking joints was being measured. Then the strength of the examined joints was determined.

\subsection{Characteristics of adhesive joints and the joined material}

Adhesive joints made of C45 low alloy steel sheets were used in the study. Chemical composition and some of its physical properties are presented in Table 1.

The joined samples were of the following dimensions: $2 \mathrm{~mm}$ thick, $100 \mathrm{~mm}$ long and 20 mm wide.

Table 1. Chemical composition and physical properties of C45 steel [14]

\begin{tabular}{|c|c|c|c|c|}
\hline \multicolumn{5}{|c|}{ C45 Steel } \\
\hline \multirow{2}{*}{\multicolumn{2}{|c|}{ Chemical composition, $\%$}} & \multicolumn{3}{|c|}{ Physical properties } \\
\hline & & Designation & Unit & Value \\
\hline $\mathrm{C}$ & 0.44 & \multirow{3}{*}{$\mathrm{Rm}$} & \multirow{3}{*}{$\mathrm{MPa}$} & \multirow{3}{*}{638} \\
\hline $\mathrm{Mn}$ & 0.55 & & & \\
\hline $\mathrm{Si}$ & 0.21 & & & \\
\hline $\mathrm{P}$ & 0.01 & \multirow{3}{*}{$\operatorname{Re}$} & \multirow{3}{*}{$\mathrm{MPa}$} & \multirow{3}{*}{369} \\
\hline $\mathrm{S}$ & 0.02 & & & \\
\hline $\mathrm{Cr}$ & 0.16 & & & \\
\hline $\mathrm{Ni}$ & 0.24 & \multirow{2}{*}{ Hardness } & \multirow{2}{*}{ HB } & \multirow{2}{*}{255} \\
\hline $\mathrm{Cu}$ & 0.07 & & & \\
\hline
\end{tabular}


The subjects of the study were lap adhesive joints subjected to shearing, whose scheme is presented in Figure 3.
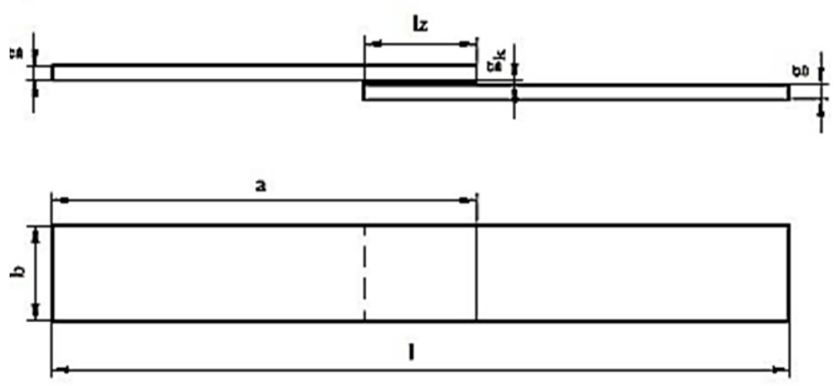

Fig. 3. Scheme of the created adhesive joints of $\mathrm{C} 45$ steel where: $\mathrm{a}=100 \mathrm{~mm}, \mathrm{~b}=20 \mathrm{~mm}, \mathrm{~g}=2 \mathrm{~mm}, \mathrm{lz}=15 \mathrm{~mm}, \mathrm{gk}=0.1 \mathrm{~mm}$

An assumed lap length was $\mathrm{lz}=15 \mathrm{~mm}$, and an adhesive-layer was about $0.1 \mathrm{~mm}$ long. Bonding field and the adhesive-layer thickness were verified after the joints were made.

Adhesive joints were made with use of the adhesive composition Epidian 57/PAC/1:1, whose preparation included mixing of the Epidian 57 epoxy resin and PAC curing agent in 1:1 weight proportion with use of a turbine bi-plate mixing arm during 3 minutes. The adhesive composition was prepared directly before the bonding process. It was applied manually on one of the surfaces to be joined with use of a polymeric toothed tray. The composition's thickness was the same on the whole joined surface. The expiry date, by then of which adhesive does not change its properties was observed during the bonding process. The bonding and curing processes were performed in stable conditions at the temperature of $25^{\circ} \pm 1{ }^{\circ} \mathrm{C}$ and $25 \% \pm 1 \%$ relative humidity. The curing time was 7 days and the pressure was 19.6 MPa. Then the strength tests were performed. Thanks to this it was possible to determine the values of failure forces, based on that, to determine the joints' strength. A trial of the lap adhesive joints' cutting was performed on the testing machine Zwick/Roell Z150, according to the norm DIN EN 1465.

\subsection{Type of mechanical working}

Surface preparation was performed by means of mechanical working with use of coated abrasives with abrasive grits of different gradation and, then, degreasing. Types of the surface treatment operations adopted in the study are presented in Table 2.

Table 2. Chemical composition and physical properties of C45 steel [14]

\begin{tabular}{|c|c|l|}
\hline No. & Variant of working & \multicolumn{1}{c|}{ Type of working } \\
\hline 1. & P40 & Mechanical working with a coated abrasive of P40 gradation \\
\hline 2. & P120 & Mechanical working with a coated abrasive of P120 gradation \\
\hline 3. & P320 & Mechanical working with a coated abrasive of P320 gradation \\
\hline 4. & P500 & Mechanical working with a coated abrasive of P500 gradation \\
\hline 5. & P40/P120 & $\begin{array}{l}\text { Mechanical working with a coated abrasive of P40 and P120 } \\
\text { gradation }\end{array}$ \\
\hline 6. & P40/P120/P320 & $\begin{array}{l}\text { Mechanical working with a coated abrasive of P40, P120 and P320 } \\
\text { gradation }\end{array}$ \\
\hline 7. & P40/P120/P320/P500 & $\begin{array}{l}\text { Mechanical working with a coated abrasive of P40, P1230, P320 } \\
\text { and P500 gradation }\end{array}$ \\
\hline
\end{tabular}


Before bonding all the samples' surfaces after mechanical working were degreased with a degreasing agent Loctite 7063 . The processes of mechanical working and degreasing are described in the references [5, 15-17]. There were 16 samples in total - 4 of each surface preparation variant served to the surface roughness examination. The remaining samples were used to make adhesive joints. There were 42 adhesive joints made in total.

\section{Test results}

\subsection{Surface roughness}

The surface roughness was examined on 4 selected samples of each surface preparation variant. Selected roughness parameters were measured: Ra, Rz, Rmax, Rq and RSm according to the standard PN-EN ISO 4287:1999/A1:2010.

According to this norm, selected parameters of the roughness profile are defined as:

- Ra - arithmetical mean of the profile's ordinates: arithmetical mean of the absolute ordinates' value inside the roughness sample length,

- $\mathrm{Rz}$ - roughness height according to 10 profile points: mean distance from the 5 peak vertices to the 5 lowest valley marks observed on the roughness sample length, measured from the reference line parallel to the average line,

- Rmax - maximum depth of a valley: it is the most important roughness depth of single pits on the whole roughness sampling length,

- $\mathrm{Rq}$ - average profile square deviation from the average line along the roughness sampling length,

- RSm - width-frequency parameter - average width of the profile elements: average value of the width of the elements inside the roughness sampling length.

Characteristics of the selected parameters of the roughness profile are presented in Table 3.

Results of the selected roughness parameters of the examined samples after different surface preparation methods are presented in Table 4. Surface roughness measurements were aimed at determining some parameters of the geometrical structure of the bonded samples' surface. Table 5 presents exemplary profilographs of C45 steels sheets after the surface treatment methods analysed above.

Table 4. Roughness parameters of C45 steel after different surface preparation methods

\begin{tabular}{|c|c|c|c|c|c|c|}
\hline \multirow{2}{*}{ No. } & \multirow{2}{*}{ Surface preparation variant } & \multicolumn{5}{|c|}{ Surface roughness parameters $[\boldsymbol{\mu m}]$} \\
\cline { 3 - 7 } & & $\mathbf{R a}$ & $\mathbf{R z}$ & $\mathbf{R m a x}$ & $\mathbf{R q}$ & $\mathbf{R S m}$ \\
\hline 1. & $\mathrm{P} 40$ & 1.907 & 13.05 & 18.01 & 2.55 & 125.50 \\
\hline 2. & $\mathrm{P} 120$ & 1.444 & 8.39 & 10.19 & 1.66 & 97.25 \\
\hline 3. & $\mathrm{P} 320$ & 1.404 & 7.50 & 11.10 & 1.80 & 111.25 \\
\hline 4. & $\mathrm{P} 500$ & 1.267 & 6.80 & 8.57 & 1.60 & 103 \\
\hline 5. & $\mathrm{P} 40 / \mathrm{P} 120$ & 1.728 & 11.80 & 16.21 & 2.47 & 134.5 \\
\hline 6. & $\mathrm{P} 40 / \mathrm{P} 120 / \mathrm{P} 320$ & 1.700 & 10.61 & 14.43 & 2.07 & 121.8 \\
\hline 7. & $\mathrm{P} 40 / \mathrm{P} 120 / \mathrm{P} 320 / \mathrm{P} 500$ & 1.467 & 9.66 & 12.96 & 1.92 & 101 \\
\hline
\end{tabular}

Based on the surface roughness measurements' results it may be observed that the highest roughness height parameters were obtained for the samples prepared by the variant: mechanical working P40 and mechanical working P40/P120. Considerably lower surface roughness parameters were obtained for the mechanical working P500. 
Table 3. Characteristics of the selected parameters of the roughness profile [18]

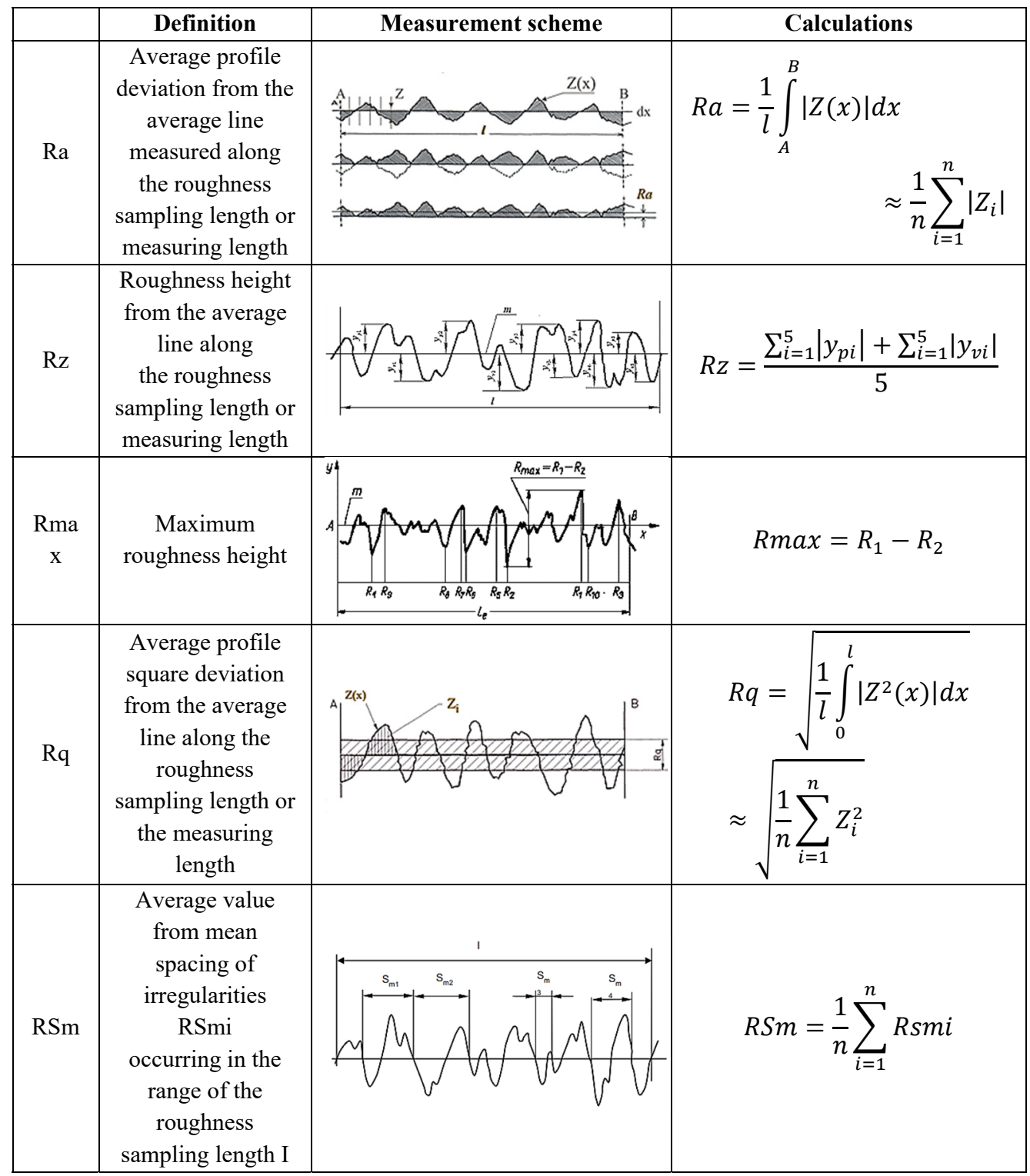

Based on that it may be observed that single-stage mechanical working lets obtain more repeatable surface roughness profile, thanks to which adhesive penetration while making adhesive joints will be better. As a result, it may be assumed that adhesive joints of elements of such roughness profiles will present better strength results. 
Table 5. Exemplary surface analysers of the examined steel sheets after different methods of surface preparation

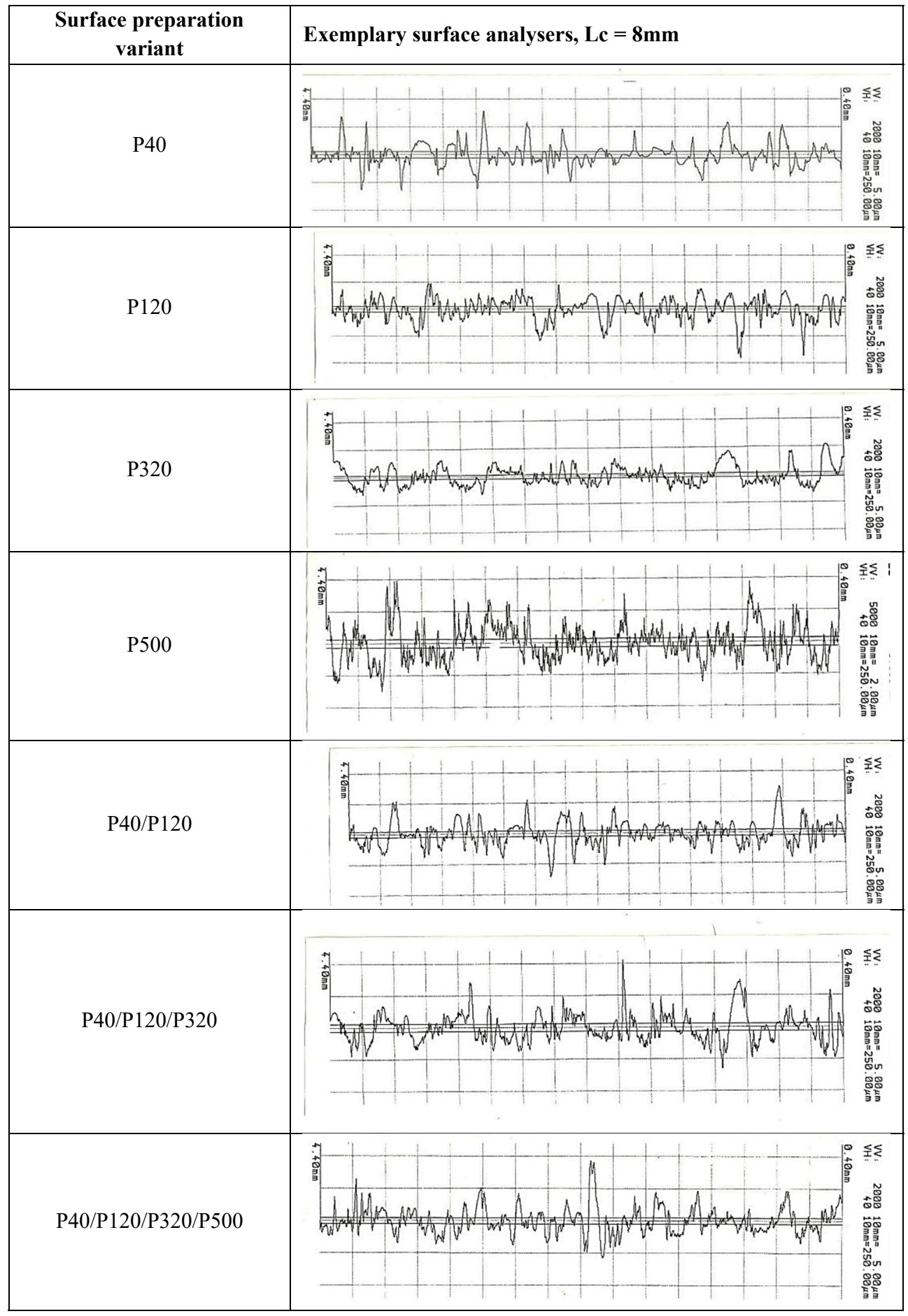




\subsection{Strength test}

Results of the strength tests conducted in the strength test are presented in Figure 4 and Table 6.

Based on the test results it may be observed that single-stage mechanical working has beneficial impact on the adhesive joints' strength of $\mathrm{C} 45$ steel in comparison with the joints in case of which the surfaces of the joined samples were subjected to multi-stage mechanical working. However, attention should be paid to substantial standard deviation of particular variants of surface preparation. The biggest discrepancies occur in case of multi-stage mechanical working, especially for mechanical working with use of coated abrasives P40 and P120.

When comparing the obtained values with the surface roughness parameters, it may be stated that they cannot serve as an indicator when it comes to the surface preparation method in all cases.

It turns out that in spite of quite low height parameters in case of the mechanical working P500, the strength of adhesive joints was the highest.

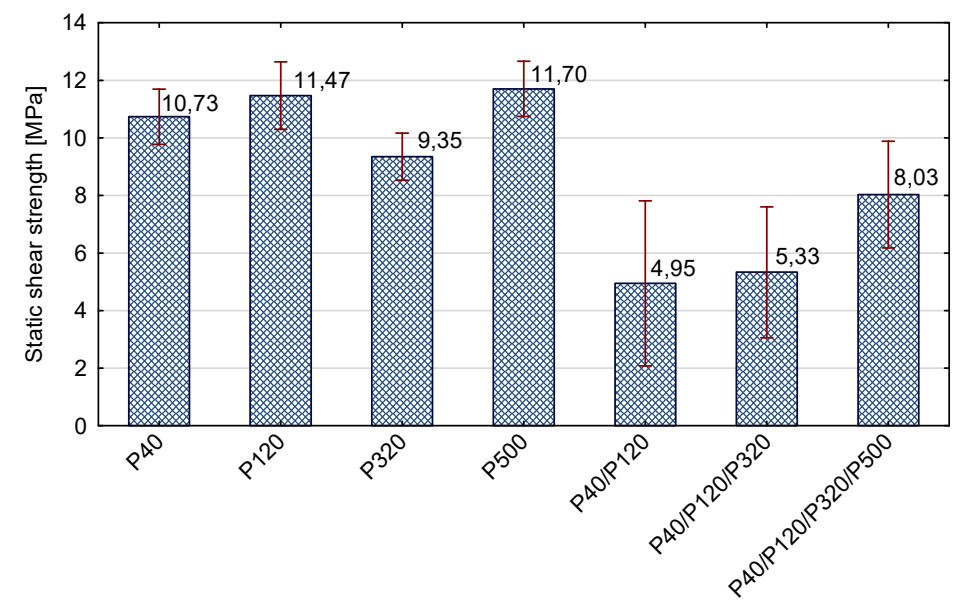

Surface preparation method

Fig. 4. Strength of the lap adhesive joint made of $\mathrm{C} 45$ steel after different surface preparation methods

Table 6. Average failure force, standard deviation and strength of adhesive joints of steel sheets made of C45 steel

\begin{tabular}{|c|c|c|c|c|c|}
\hline \multirow{2}{*}{ No. } & \multirow{2}{*}{$\begin{array}{c}\text { Surface preparation } \\
\text { variant }\end{array}$} & \multicolumn{2}{|c|}{ Failure force, N } & \multicolumn{2}{|c|}{ Shear strength, MPa } \\
\cline { 3 - 6 } & Mean & $\begin{array}{c}\text { Standard } \\
\text { deviation }\end{array}$ & Mean & $\begin{array}{c}\text { Standard } \\
\text { deviation }\end{array}$ \\
\hline 1. & P40 & 854.03 & 369 & 10.73 & 1.0 \\
\hline 2. & P120 & 810.90 & 455 & 11.47 & 1.2 \\
\hline 3. & P320 & 559.78 & 224 & 9.35 & 0.8 \\
\hline 4. & P500 & 1323.60 & 140 & 11.70 & 1.0 \\
\hline 5. & P40/P120 & 490.32 & 817 & 4.95 & 2.9 \\
\hline 6. & P40/P120/P320 & 272.13 & 220 & 5.33 & 2.3 \\
\hline 7. & P40/P120/P320/P500 & 324.35 & 177 & 8.03 & 1.9 \\
\hline
\end{tabular}


Geometric structure of surface, as well as geometric dimensions of micro irregularities has to be taken into consideration too as they may be crucial due to possible penetration by adhesive. When analysing surface analysers, it may be observed that the structure after mechanical working with use of an abrasive of P500 gradation is different than the one after other variants of working. Such structure may ensure better mechanical adhesion in comparison to the abrasives of different gradation.

Also, it may be observed that in terms of the strength of adhesive joint of the joined materials, beneficial surface structure was obtained for mechanical working with an abrasive of P120 gradation. However, in order to confirm the existence of similarities or discrepancies between the obtained strength of the adhesive joints, it is necessary to conduct a statistical analysis of the obtained results.

\subsection{Statistical analysis of the obtained results}

Strength of adhesive joints is a vital criterion of such joints' assessment. Shear strength is defined as a deviant strain of an object caused by tangential stresses. After strength tests, an analytical analysis at a confidence level $\alpha=0.05$ was obtained. In the beginning, the analytical analysis was conducted in order to check the normality of distribution with use of a Shapiro-Wilk normality test for small samples. Its results are presented in Table 7.

Table 7. Normality test - adhesive joints' strength

\begin{tabular}{|c|c|c|c|}
\hline $\begin{array}{c}\text { Surface preparation } \\
\text { variant }\end{array}$ & $\begin{array}{c}\text { Shapiro-Wilk } \\
\text { statistics W }\end{array}$ & $\begin{array}{c}\text { Probability } \\
\text { level p }\end{array}$ & $\begin{array}{c}\text { Normality of } \\
\text { distribution }\end{array}$ \\
\hline P40 & 0.927 & 0.555 & Yes \\
\hline P120 & 0.993 & 0.996 & Yes \\
\hline P320 & 0.928 & 0.565 & Yes \\
\hline P500 & 0.857 & 0.180 & Yes \\
\hline P40/P120 & 0.918 & 0.489 & Yes \\
\hline P40/P120/P320 & 0.970 & 0.894 & Yes \\
\hline P40/P120/P320/P500 & 0.908 & 0.423 & Yes \\
\hline
\end{tabular}

Compliance analysis of the empirical distribution with the normal distribution examined by means of the Shapiro-Wilk test did not reject the hypothesis of the normality of distribution of the adhesive joints' strength for the examined methods of surface preparation ( ). Another stage of study was to check the variance homogeneity with use of the Levene's test, whose results are presented in Table 8.

Table 8. Variance homogeneity Levene's test

\begin{tabular}{|c|c|c|c|c|c|c|c|c|}
\hline & $\begin{array}{c}\text { SS } \\
\text { Effect }\end{array}$ & $\begin{array}{c}\text { df } \\
\text { Effect }\end{array}$ & $\begin{array}{c}\text { MS } \\
\text { Effect }\end{array}$ & $\begin{array}{c}\text { SS } \\
\text { Error }\end{array}$ & $\begin{array}{c}\text { df } \\
\text { Error }\end{array}$ & $\begin{array}{c}\text { MS } \\
\text { Error }\end{array}$ & F & p \\
\hline Shear strength & 9.16 & 6 & 1.53 & 38.66 & 35 & 1.105 & 1.382 & 0.249 \\
\hline
\end{tabular}

The Levene's test does not reject the variance equality hypothesis. Taking this into consideration, the next step was to conduct the ANOVA statistics in order to check the impact of the surface preparation of the joined elements on the adhesive joints' strength. The Tukey's and HSD test was conducted and the interaction graph was drawn in order to interpret and compare the results precisely. 
Table 9. Tukey's Honestly Significant Difference test at $\alpha=0.05$

\begin{tabular}{|l|c|c|c|c|c|c|c|}
\hline Surface preparation variant & $\{\mathbf{1}\}$ & $\{\mathbf{2}\}$ & $\{\mathbf{3}\}$ & $\{\mathbf{4}\}$ & $\{\mathbf{5}\}$ & $\{\mathbf{6}\}$ & $\{\mathbf{7}\}$ \\
\hline P40 $\{1\}$ & & 0.989 & 0.801 & 0.956 & 0.001 & 0.001 & 0.123 \\
\hline P120 $\{2\}$ & 0.989 & & 0.357 & 1.000 & 0.001 & 0.001 & 0.022 \\
\hline P320 $\{3\}$ & 0.801 & 0.357 & & 0.243 & 0.002 & 0.005 & 0.835 \\
\hline P500 $\{4\}$ & 0.956 & 1.000 & 0.243 & & 0.001 & 0.001 & 0.012 \\
\hline P40/P120 $\{5\}$ & 0.001 & 0.001 & 0.002 & 0.001 & & 1.000 & 0.052 \\
\hline P40/P120/P320 \{6\} & 0.001 & 0.001 & 0.005 & 0.001 & 1.000 & & 0.123 \\
\hline P40/P120/P320/P500 \{7\} & 0.123 & 0.022 & 0.835 & 0.012 & 0.052 & 0.123 & \\
\hline
\end{tabular}

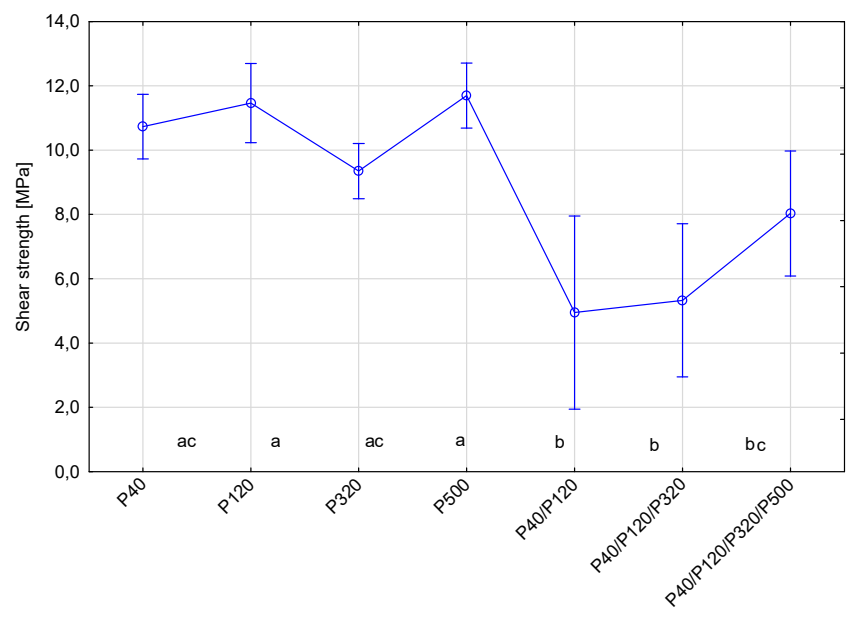

Surface preparation method

Fig. 5. Graph of interactions of average values of the adhesive joints' strength with designated homogenous groups

Table 10. The post-hoc Tukey's test designating homogenous groups

\begin{tabular}{|c|c|c|c|c|c|}
\hline No. & Surface preparation & Average shear strength & $\mathbf{a}$ & $\mathbf{b}$ & $\mathbf{c}$ \\
\hline 1 & $\mathrm{P} 40$ & 10.73 & $* * * *$ & & $* * * *$ \\
\hline 2 & $\mathrm{P} 120$ & 11.47 & $* * * *$ & & \\
\hline 3 & $\mathrm{P} 320$ & 9.35 & $* * * *$ & & $* * * *$ \\
\hline 4 & $\mathrm{P} 500$ & 11.70 & $* * * *$ & & \\
\hline 5 & $\mathrm{P} 40 / \mathrm{P} 120$ & 4.95 & & $* * * *$ & \\
\hline 6 & $\mathrm{P} 40 / \mathrm{P} 120 / \mathrm{P} 320$ & 5.33 & & $* * * *$ & \\
\hline 7 & $\mathrm{P} 40 / \mathrm{P} 120 / \mathrm{P} 320 / \mathrm{P} 500$ & 8.03 & & $* * * *$ & $* * * *$ \\
\hline
\end{tabular}

Based on the obtained results, it may be observed that ANOVA showed significant interaction between the surface preparation method and the adhesive joints' strength. Also, strength of the adhesive joints of samples whose surface had been prepared by means of a single-stage mechanical working differs significantly from strength of the adhesive joints of samples whose surface had been prepared by means of multi-stage mechanical working. Only 
in case of mechanical working designated as P40/P120/P320/P500, a similar result with the working P40 and P320 was observed (they are in one homogenous group).

\section{Conclusions}

The study was related with the impact of one-stage or multi stage abrasive machining on the static strength of the lap adhesive joints of C45 steel. Surface treatment method was a variable factor in the study. The other factors like: type of adhesive and other conditions of the joints making were invariable during the study. A method of the steel sheet surface preparation used in the study was one- and multi-stage mechanical working with use of coated abrasives with abrasive grits of different gradation. Also, measurements of the surface roughness after the considered types of the preparatory treatment were carried out.

Based on the research, it was observed that adhesive joints of the $\mathrm{C} 45$ steel sheets, whose surface was subjected to mechanical working with a P500 abrasive (11.70 MPa) were the strongest. Statistically insignificant strength was also obtained for adhesive joints of the element subjected to mechanical working with a P120 abrasive (11.47 MPa). The lowest strength was obtained in case of the joined elements whose surface was prepared in a few stages. What is more, this method is more time-consuming. In addition, when analysing the statistical analysis' results, it was observed that the greatest discrepancies occurred in case of treatment with use of several abrasives. The highest repeatability of results was obtained in case of working for which the strength was the highest.

To sum up, abrasives of higher gradation used during the surface preparation have beneficial impact on the adhesive joints of $\mathrm{C} 45$ steel sheets. Test results presented above were obtained for the presented conditions of the adhesive joints' making. In the situations when the adhesive joint must carry a specified weight of a known value, it is possible to use the adhesive technology in joining sheets made of low-carbon steel. It will also let avoid difficulties connected with other welding methods.

\section{References}

1. Rudawska, Selected Issues in Constituting Homogeneous and Hybrid Adhesive Joints. (Lublin University of Technology, Lublin, 2013)

2. Borsellino, et al., Comparisons of processing and strength properties of two adhesive systems for composite joints. Int. J. Adhes. Adhes. 27.6, 446-457 (2007)

3. Dmitruk, P. Mayer, J. Pach., Pull-off strength of thermoplastic fiber-reinforced composite coatings. J. Adhes. Sci. Technol. 32.9, 997-1006 (2018)

4. A. Baldan, Adhesively-bonded joints and repairs in metallic alloys, polymers and composite materials: adhesives, adhesion theories and surface pretreatment. J. Mater. Sci. 39.1, 1-49 (2004)

5. L.F.M. da Silva, R.J.C. Carbas, G.W. Critchlow, M.A.V. Figueiredo, K. Brown, Effect of material, geometry, surface treatment and environment on the shear strength of single lap joints. Int. J. Adhes. Adhes. 29.6, 621-632 (2009)

6. A. Rudawska, Selected aspects of the effect of mechanical treatment on surface roughness and adhesive joint strength of steel sheets. Int. J. Adhes. Adhes. 50, 235-243 (2014)

7. L.H. Lee, ed. Adhesive bonding. (Springer Science \& Business Media, 2013)

8. A.J. Kinloch, Adhesion and adhesives: science and technology. (Springer Science \& Business Media, 2012) 
9. G.W. Critchlow, K.A. Yendall, D. Barani, A. Quinn, F. Adrews, Strategies for the replacement of chromic acid anodizing for the structural bonding of aluminium alloy. Int. J. Adhes. Adhes. 26 (2006)

10. M. Rucka, J. Lachowicz, E. Wojtczak., Lamb wave propagation in a single lap adhesive joint. Shell Structures: Theory and Applications Volume 4: Proceedings of the 11th International Conference Shell Structures: Theory and Applications, (2017)

11. M. Shahid, S. A. Hashim. Effect of surface roughness on the strength of cleavage joints. Int. J. Adhes. Adhes. 22.3, 235-244 (2002)

12. A. Rudawska, M. Reszka, T. Warda, I. Miturska, J. Szabelski, A. Skoczylas, D. Stancekova, Milling as a method of surface pre-treatment of steel for adhesive bonding. J. Adhes. Sci. Technol., 23, 2619-2636 (2016)

13. J.M. Arenas, J.N. Julián, A. Cristina, Optimum adhesive thickness in structural adhesives joints using statistical techniques based on Weibull distribution. Int. J. Adhes. Adhes. 30.3, 160-165 (2010)

14. U.A. Khashaba, et al., Machinability analysis in drilling woven GFR/epoxy composites: Part I-Effect of machining parameters. Composites Part A. 41.3, 391-400 (2010)

15. W. Zielecki, et al., Surface topography effect on strength of lap adhesive joints after mechanical pre-treatment. ACME 13.2, 175-185 (2013)

16. G. Rotella, M. Alfano, T. Schiefer, I. Jansen, Evaluation of mechanical and laser surface pre-treatments on the strength of adhesive bonded steel joints for automotive industry, . J. Adhes. Sci. Technol., 30, 747-758 (2016)

17. P. Davies, et al., Influence of adhesive bond line thickness on joint strength. Int. J. Adhes. Adhes. 29.7, 724-736 (2009)

18. M.W. Sayers, Guidelines for conducting and calibrating road roughness measurements. (The World Bank Washington, D.C., U.S.A 1986) 